\title{
Sufre, soporta y padece: fuentes latinas de la resignación en los refranes españoles
}

\author{
Suffer, Bear, and Endure: \\ Latin Sources of Resignation in Spanish Proverbs
}

\author{
Xavier Pascual-López \\ Departament of Romance Studies, Adam Mickiewicz University, \\ al. Niepodlegości 4, 61-874, Poznań, Poland \\ e-mail: xavpas@amu.edu.pl
}

\begin{abstract}
Spanish refranero forms a sort of code whose aim is to guide and control the conduct of the members of the linguistic community that has coined these proverbs and uses them. A great part of the ideology that can be gathered from Spanish proverbs was already present in Classical culture. Therefore my overall objective is to trace the Classical precedents of Spanish proverbs. Particularly this paper aims to find in Latin language and literature formal or ideological precursors of a certain amount of Spanish proverbs concerning the stoic attitude we should take in order to confront misfortune. This attitude is based on facing with resignation what fate holds in store for us and it results in accepting pain as an essential part of human existence, promoting a conformist behavior that restrains aspirations to better conditions and makes it unlikely that the establishment will be broken.
\end{abstract}

Keywords: paremiology, Spanish proverbs, Latin literature, misfortune, resignation, stoicism

\section{INTRODUCCIÓN}

El conjunto de paremias ${ }^{1}$ de una lengua constituye un testimonio del pensamiento, las costumbres y la organización social de una comunidad lingüística, ya

\footnotetext{
${ }^{1}$ No entraremos en cuestiones terminológicas y tipológicas, sino que emplearemos el término paremia como modo hiperonímico de referirnos a este tipo de fraseologismo que, según el manual ya clásico de Corpas Pastor (1996, pp. 132-133), constituye un enunciado en sí mismo, goza de autonomía textual y tiene significado referencial más allá del sentido que pueda tener en el contexto en el que se inserta. A veces usaremos en un sentido más estricto la voz refrán, por ser el término tradicional y más natural. Para una clasificación más detallada de las paremias, remitimos a Sevilla Muñoz (1988) y Sevilla Muñoz \& Crida Álvarez (2013).
} 
que refleja y perdura sus códigos de conducta y sus valores morales, llegando a constituir "un microcosmos cultural en el que varios códigos específicos se encuentran implicados" (Forgas Berdet, 1992, p. 296).

El análisis cultural de los fraseologismos en general se ha realizado desde tres perspectivas. Por un lado, la sociolingüística se centra en la particularidad de su empleo en la ejecución lingüística, por parte de unos hablantes que pertenecen a un grupo social determinado y emplea estas unidades fraseológicas en un contexto de uso particular y con unos objetivos comunicativos concretos (Arewa \& Dundes, 1964; Kirshenblatt-Gimblett, 1973; Briggs, 1985; Pawley \& Syder, 2000; Wray \& Perkins, 2000; Penadés Martínez, 2006; Norrick, 2007; Veyrat Rigat, 2008; Anscombre, 2010; Domínguez Barajas, 2010). Por otro lado, el cognitivismo pone el acento en el hecho de que los procesos mentales requeridos para acuñar estas unidades e interpretarlas pueden o bien responder a universales del pensamiento, o bien estar determinados culturalmente y estar ligados, por ende, a una cultura concreta (Telija, Bragina, Oparina \& Sandomirskaja, 1998; Dobrovol'skij \& Piirainen, 2005; Langlotz, 2006; Piirainen, 2008). Por último, la etnolingüística se centra en cómo las unidades fraseológicas reflejan y ayudar a regular el orden socio-cultural dentro del cual han sido acuñadas, dando una visión sesgada de la realidad que no solo es propia de la parcialidad de la cultura, sino que también responde a diferencias de corte social (en especial, relaciones de poder) (Forgas Berdet, 1982; White, 1987; Calero Fernández, 1991; Pascual López, 2012).

El presente trabajo se inscribe en esta tercera perspectiva y, en concreto, en la identificación de las posibles fuentes de las que bebe el refranero español, ya sea de forma directa (con la traducción y/o adaptación de paremias) o indirecta (mediante la incorporación de ideas y tópicos preexistentes) ${ }^{2}$. En un artículo precedente (Pascual López, 2015), iniciamos la localización en la cultura clásica de los precursores (formales o ideológicos) de algunas paremias españolas versadas sobre la actitud con que hay que encarar los reverses de la fortuna. Sirviendo de complemento a ese otro artículo, el objetivo del presente es rastrear los precedentes latinos de otras paremias españolas que complementan a aquellas y que abogan claramente por la resignación a la propia suerte e instituyen el sufrimiento como inevitable. Para ello, procederemos a la clasificación de estas paremias según su sentido y las fuentes con las que pueden relacionarse ${ }^{3}$.

\footnotetext{
${ }^{2}$ En muchas ocasiones puede resultar difícil dilucidar si dos paremias equivalentes realmente tienen un origen común, o bien tienen que entenderse como casos de poligénesis, es decir, de cristialización paremiológica de tópicos que imperan en la mentalidad y en la cultura, los cuales han dado como resultado paremias sinónimas pero sin relación de continuidad formal. Sobre esta cuestión, véase Pascual Lópe (2012, p. 14).

${ }^{3}$ En el caso de los testimonios clásicos que aduciremos, no todos ellos son unidades formularias ni pueden considerarse paremias, sino que en muchas ocasiones son variaciones literarias sobre lugares comunes que, en algunos casos pudieron llegar a proverbializarse.
} 


\section{LA ATARAXIA COMO IDEAL}

El estoicismo concibe al hombre como un ser racional que puede poseer la razón (logos) de forma más o menos firme en función de su grado de sabiduría. Es esta "razón recta" lo que le hará percibir el mundo de acuerdo con los preceptos del estoicismo (Long, 2004 [1975], pp. 173-175). Para los estoicos (y epicúreos), la eudaimonía (felicidad) es el mayor bien de que pueden gozar los seres humanos, pero solo la hallarán gracias al ejercicio de la virtud. A su vez, la virtud estoica (y, por tanto, la felicidad) se sustenta sobre tres pilares fundamentales: la autarquía (autosuficiencia), la ataraxia (imperturbabilidad, impasividad) y la apatía (desapasionamiento, falta de emoción) ( $c f$. Epict. Ench. 33-34). En otras palabras, el ser virtuoso y feliz es aquel que se basta a sí mismo para dominar sus pasiones y no dejarse conmover (aunque eso no significa que sea un ser insensible) ni por la adversidad ni por la prosperidad, alcanzando un estado de equilibrio que conduce finalmente a la felicidad (Long, 2004 [1975], pp. 200-202).

La idea se halla desde los albores de los testimonios escritos (ante el infortunio,

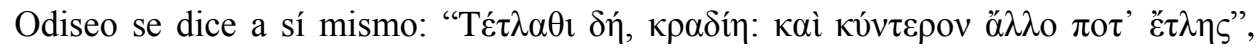
'Aguanta, corazón, pues ya en otro momento has aguantado algo peor', Hom. Od. 20.18) y, desde antiguo, se proverbializó como lema del estoicismo en la formula-

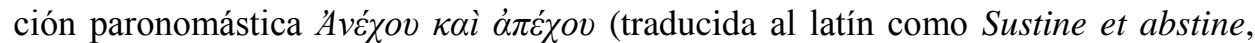
'Soporta y abstente', $c f$. Erasm. Adag. 2.7.13; Walther, 1963-1969, no 30937a'). Con esta máxima se hace un encomio de la ataraxia y la apatía como ideales de vida, indicando que la adversidad se debe soportar sin dejar que el alma se turbe, al tiempo que señala la conveniencia de que el ser virtuoso debe abstenerse de los placeres mundanos que podrían perturbar la virtud.

Esta divisa en ocasiones se ha atribuido al fundador de esta escuela, Zenón de Citio (s. IV a. C.), pero más comúnmente se atribuye al estoico tardío Epicteto ${ }^{6}$, tal como hace Aulo Gelio (17.19.5-6):

[...] Epicteto solía decir: «Hay dos vicios que son, con mucho, los más graves y atroces de todos: la intolerancia y la incontinencia, cuando no toleramos ni soportamos las injurias que nos infligen o no nos apartamos de las cosas y placeres de los que debemos apartarnos. Por tanto - dice- si alguien guardara en su corazón estas dos palabras y procurara dominarlas y observarlas en su interior, éste estará siempre libre de errores y vivirá la

\footnotetext{
${ }^{4}$ Salvo que se indique lo contrario, las traducciones del latín y del griego son propias y, más que el efecto literario, buscan la literalidad junto con la traducción constante de ciertos términos.

${ }^{5}$ Se recoge minoritariamente la versión con el orden inverso (Abstine (et) sustine, Sánchez Doncel, 2003, n ${ }^{\circ}$ 141; Tosi, 2007 [1991], $\mathrm{n}^{\circ}$ 1664, quien, además, menciona diferentes obras medievales en las que se cita).

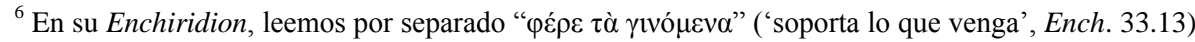

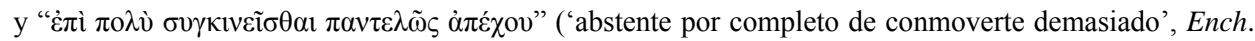
33.10).
} 
vida más apacible.» Y decía estas dos palabras: Anéchou y apéchou. (trad. de Ortiz García, 1995, p. 231)

A la difusión de esta máxima (en su versión latina) contribuyó perentoriamente el humanista italiano del siglo XVI Andrea Alciato, que lo ilustró en uno de sus emblemas y lo comentó atribuyéndolo a Epicteto. Los emblemas de Alciato fueron pronto traducidos al español, favoreciendo la transmisión de la versión española Sufre y refrénate:

Sustine et abstine

Et toleranda homini tristis fortuna ferendo est, Et nimium felix saepe timenda fuit.

Sustine (Epictetus dicebat) \& abstine. oportet Multa pati, illicitis absque tenere manus.

Sic ducis imperium vinctus fert poplite taurus In dextro: sic se continent a gravidis.

(Alciato, 1550, p. 41)

\section{Suffre y refrénate}

Como suffrirse deue la Fortuna

Contraria, ansi la prospera temerse.

Dize Epícteto no aya cosa alguna

En que suffrir no cure y detenerse

Quien a'l consejo santo no repunna.

Como a'l pastor el toro (en contenerse

De la preñada vaca) es subjettado

La rodilla derecha andando atado.

(Alciato, 1549, p. 208)

Si la famosa formulación realmente se debe a Epicteto, es obvio que el fondo conceptual es preexistente, dado que contamos con numerosos pasajes literarios anteriores en los que se recuerda dicha máxima, especialmente en lo referente a la ataraxia (es decir, a la parte representada por el imperativo sustine), ya no solo por su sentido, sino también por la técnica de composición consistente en coordinar dos imperativos. Por ejemplo, al principio de la Eneida, Eneas anima a sus compañeros de viaje señalándoles que hay que soportar las desgracias que les acechan porque todos los riesgos que corren en esos momentos son el camino que los conducirá al Lacio, donde los hados les serán propicios, concluyendo su parlamento con estas palabras: "Durate, et vosmet rebus servate secundis" ('Manteneos firmes y guardaos para momentos más prósperos', Verg. Aen. 1.207). Por su parte, Horacio insta a la imperturbabilidad con la pareja de imperativos "Persta atque obdura" ("Persiste y aguanta', Serm. 2.5.39) ${ }^{7}$, al tiempo que Ovidio utiliza en dos ocasiones la formulación paralela "Perfer et obdura": una vez señalando el beneficio que surge del dolor 8 ("Perfer et obdura; dolor hic tibi proderit olim", 'Resiste y aguanta: este dolor te será

\footnotetext{
${ }^{7}$ Además de señalar sus versiones y su pervivencia, Jiménez Gazapo, Morillas Gómez \& Morillo Ruiz (2012) indican que esta expresión proverbializada "puede aparecer en un contexto amatorio, como consejo al amante desdeñado, o aplicada a las circunstancias adversas, como invitación a la paciencia. En este caso Horacio le da un giro paródico, al recomendar la persistencia en el arte de cazar herencias" (p. 231).

${ }^{8}$ A esta cuestión volveremos en el último apartado.
} 
provechoso algún día', Am. 3.11a.7) y otra comparando el sufrimiento actual con otros pasados ("Perfer et obdura; multo graviore tulisti", 'Resiste y aguanta: cosas mucho más pesadas has soportado', Tris. 5.11.7) ${ }^{9}$.

En cuanto a la lengua española, la frase proverbial latina Sustine et abstine se usa como latinismo en español (Doval, 1996, s. v.) ${ }^{10}$, pero también se recoge su uso en la traducción Sufre y abstente (Doval, 1997, $\left.\mathrm{n}^{\mathrm{o}} 439\right)^{11}$. Sin embargo, el refranero prefiere versiones más creativas que se adecuan mejor a las características prosódicas de los refranes. Pero igual que hemos visto en los testimonios latinos, es la parte referida a la ataraxia lo que suele permanecer, ya que el denominador común de estas versiones españolas es la adaptación más o menos constante de sustine como sufre; en cambio, abstine es objeto de múltiples versiones, muchas veces sin relación semántica.

El refrán El bueno sufre y sostiene, que el malo no puede $(48105)^{12}$ relaciona esta actitud vital con la virtud, ya que la capacidad para seguir esta regla estoica se restringe a los virtuosos. En este caso, resulta curioso el segundo verbo, que no es sino la versión patrimonial de sustine y cuya presencia debe entenderse como un arcaísmo semántico. Se registra también la versión El bueno sufre, que el malo no puede (Sbarbi, 1943, p. 159), en la que el ritmo y la rima se destruyen al no aparecer el segundo elemento; la existencia de esta versión puede tener que ver con el poco peso semántico del verbo sostiene en el refrán anterior, en tanto que remite sin duda a su sentido etimológico y no acaba de ser un uso habitual de este verbo.

Al patetismo que impera en las versiones latinas, el refranero español prefiere darle una pizca de esperanza, dejando la puerta abierta a una mejor suerte en el futuro. Esto se observa en los refranes que adaptan la unidad latina como sufre y espera (Mientras el mal persevera, sufre y espera, 48115; Cuando la adversidad venga, sufre y espera, y suceda al cabo lo que Dios quiera, 48140), así como en otros en los que se prescinde de la coordinación de imperativos y se proyecta la espera hacia el futuro (Sufre hoy; que llegará mañana, 48108; Sufra quien penas

${ }^{9}$ Hacia el final veremos algunos pasajes en los que se afirma que del recuerdo del dolor pasado puede obtenerse placer. Además, Ovidio recurre al tópico en otras ocasiones: rememorando a Homero (Od. 20.18, véase supra): "Hoc quoque, Naso, feres, etenim peiora tulisti" ('También aguantarás esto, Nasón, pues cosas peores has aguantado', Pont. 3.7.13) y, en un cuarto pasaje, empleando sustinere (el verbo de la traducción ortodoxa del lema estoico): "Sustineas ut onus, nitendum vertice pleno est, / aut, flecti nervos si patiere, cades" ('Para soportar la carga debes mantener la cabeza bien derecha o caerás si a la vez relajas los músculos', Pont. 2.7.77). Este verbo también será utilizado por Kempis: "Certa viriliter, sustine patienter" ('Lucha virilmente, sufre con paciencia', Imitat. Christ. 3.19.16).

${ }^{10}$ Así lo atestiguan los corpora digitales de la RAE. En el CREA aparece esta expresión latina en un único documento junto a la traducción "soporta y abstente", pero el CORDE da un mayor número de testimonios: encontramos sustine et abstine en once casos y la variante abstine et sustine en uno.

${ }^{11}$ La misma fuente da otras dos variantes: Soporta y abstente, Abstente y sufre.

${ }^{12}$ Las paremias españolas seguidas de un número sin indicación de fuente remiten a la numeración con la que aparecen en Martínez Kleiser (1953). 
tiene, que un tiempo tras otro viene, 48106; Sufrir convién; que tras el mal viene el bien, 48107; Sufre con cordura, hasta ver la tuya, 48111; A quien esperar y sufrir puede, todo en su tiempo le viene, 48177). En este sentido, estos refranes están más cercanos a la formulación de Virgilio ya citada, en la que Eneas recurría al tópico para alentar a los suyos con la promesa de un futuro mejor.

Esta esperanza se ve en otros refranes que instan a sufrir en silencio (Sufrir y callar, y mejor tiempo esperar, 48110; Sufrir en silencio, y esperar mejor tiempo, 48109), haciendo patente la apatía con la que debe soportarse el dolor, que no debe degenerar en quejidos o protestas ${ }^{13}$. Salvo una excepción parcial en la que se mantiene una forma de imperativo (Sufre callando lo que no puedes remediar hablando, 8780), en estos casos se emplea otras formas verbales (Sufro y callo, por el tiempo en que me hallo[; que si en otro mejor me hallara, ni sufriera ni callara], 4804548046; Quien sufrió y calló, lo que quiso vio, 48167; Quien tiene un duro, lo gasta; y quien no, suspira y calla, 48023).

También en esa línea más optimista tenemos refranes que recurren al oxímoron gracias a la coordinación de los verbos Sufre y gozarás (57246). En este grupo se perfila el tópico del homo viator, en el que la vida se concibe como un camino por el que avanza el ser humano (Anda y llegarás; sufre y gozarás, 22529), pero especialmente aparecen resonancias cristianas (Sufre acá, y allá gozarás, 10765). La ataraxia estoica es adoptada por el cristianismo con el tópico de la vida como un valle de lágrimas, cuyo sentido es sufrir en este mundo con la esperanza de gozar del paraíso después de la muerte (Miguel, 2000, pp. 69-71). Por tanto, en la adaptación del tópico estoico no pueden pasarse por alto otras influencias que han configurado el saber popular y la cultura hispana.

En uno de los pasajes citados -y en otros que veremos más adelante-, Ovidio nos decía que el sufrimiento actual podría ser provechoso en el futuro. En esta línea se inscribe la recompensa cristiana del paraíso que intuimos en los refranes anteriores y en otros en los que el beneficio es la tranquilidad de ánimo (Sufre y vivirás vida de paz, 48112) o la aceptación social (Sé sufrido y serás querido, 48113).

En "Las ranas pidieron un rey", Fedro reformula una fábula que -según cuenta el fabulista romano- Esopo se inventó cuando los atenienses perdieron su libertad bajo la tiranía de Pisístrato y empezaban a quejarse, ya que "gravis omnino insuetis onus" ('la carga es pesada para los no acostumbrados a ella', Phaedr. 1.2.7-8). A diferencia del texto esópico, Fedro se centra en esta carga a la que hay que habituarse, concluyendo su versión con una moraleja ("Hoc sustinete maius ne veniat malum”, 'Soportad este mal, no sea que venga otro mayor', Phaedr. 1.2.31) de índole mucho más estoica que la proporcionada por Esopo (44), que se centra en la nece-

\footnotetext{
${ }^{13}$ En este sentido, Epicteto (Ench. 33.2) considera oportunos la parquedad de palabras y el silencio.
} 
sidad de elegir gobernantes honestos. Que al principio aparezca el sustantivo onus y al final el verbo sustinere hace pensar que Fedro insertó conscientemente su fábula en la tradición de la que nos ocupamos ahora.

De estas dos citas de Fedro, la primera no se proverbializó y los escasos equivalentes españoles no tienen relación formal, sino que solo remedan la idea de que es necesario acostumbrarse a los sinsabores ${ }^{14}$; en cambio, la moraleja, como puede funcionar de forma autónoma y es más susceptible de ser repetida, sí llegó a proverbializarse, por lo cual puede verse su pervivencia en nuestro refranero. El refrán que guarda más parecido formal es Sufre lo poco, por no venir a sufrir lo mucho (48103), pero la mayoría se especializa en el ámbito de las relaciones de poder (amo-criado), recuperando de alguna manera el contexto original de la fábula de la que se desgajó la moraleja (Conservemos este señor, no venga otro peor, 48104; Mal amo has de guardar, por miedo de empeorar, 14285); a veces se introduce un elemento cristiano que alinea la religión con el poder (Rogad por el mal señor, por miedo de otro peor, 4236; Dios conserve a mi señor, por miedo de otro peor, 14287), porque parece una ley natural que cualquier cambio que se produzca al respeto va a ser negativo (Cuando es malo un señor, tras él viene otro peor, 4237; Se va un señor, y viene otro peor, 4238).

Aquí cabría añadir una variación - un tanto artificial-en la que se aplica al ámbito vecinal (Cuando tovieres un mal vecino, non ruegues que te se vaya, non venga otro peor, 38193), así como uno de los pocos refranes en parte subversivos, ya que se apropia del tópico de sufrir lo malo añadiéndole la esperanza de una mejoría para quien se la procure (Mientras tienes ruin señor, sufre y busca otro mejor, 14286).

\section{UNA FATALIDAD PROVIDENCIAL}

En una parodia del discurso trágico, el avaro Euclión - que esconde una olla llena de oro- proclama patética e hipócritamente que se resigna y se conforma con su pobreza: "pauper sum; fateor, patior; quod di dant fero" ("soy pobre; lo admito, sufro; soporto lo que me envían los dioses', Plaut. Aul. 88). En este pasaje, Plauto se hace eco de uno de los tópicos de la Antigüedad: la fatalidad y la providencia divina $^{15}$, que en la filosofía estoica se identifican como la misma entidad. El cosmos estoico está sometido a un orden necesario e inalterable que la providencia divina ha instituido por considerarlo el mejor de todos los órdenes posibles (Sellars, 2006,

\footnotetext{
${ }^{14}$ Por ejemplo, Lleve carga el borrico, y el buey are desde chico (5398).

${ }^{15}$ Los ejemplos son innumerables, pero podemos remitir a una de las obras fundacionales de la

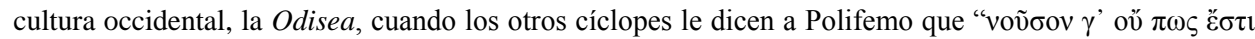
$\Delta$ iò $\mu \varepsilon \gamma \alpha \dot{\lambda}$ ov $\alpha \dot{\lambda} \varepsilon \dot{\alpha} \alpha \sigma \alpha$ l” ('es imposible rehuir el daño que manda el gran Zeus', Hom. Od. 9.411). Un repaso de este tópico se encuentra en Tosi (2007 [1991], nº 852).
} 
pp. 99-101; Long, 2004 [1975], pp. 162-168; Epict. Ench. 31.1-2; cf. Pruss \& Gale, 2005). En este sentido, anteriormente hemos analizado muestras clásicas y refranes españoles en torno al poco poder de decisión que se asigna a los humanos (Pascual López, 2015, pp. 32-34). Completando lo dicho allí, este verso de Plauto nos introduce el uso del verbo ferre como sinónimo de los que ya hemos visto (sustinere, etc.), al tiempo que recuerda a todas luces el uso del griego $\varphi \varepsilon ́ \rho \varepsilon \imath v$ en pasajes trágicos que Plauto podría tener en mente ${ }^{16}$.

Lo inexorable del destino se ve, por ejemplo, en un verso de Terencio: "Nunc cum non queo, animo aequo fero" ('Ahora que no puedo [cambiarlo], lo soporto con ánimo sereno', Adelph. 738) ${ }^{17}$; y el mismo verbo de estas fuentes reaparece en un par de sentencias de Publilio Siro que hacen explícita dicha inalterabilidad: Feras, non culpes, quod vitari/mutari non potest ${ }^{18}$ ('Soporta, no desapruebes, lo que no se puede evitar/cambiar', F11), Mutare quod non possis, ut natum est feras ('Lo que no puedas cambiar, sopórtalo tal como se ha producido', M62) ${ }^{19}$. Como paremias me-

${ }^{16}$ Son muy numerosos, pero puede citarse, por ejemplo, una sentenciosa afirmación del coro en

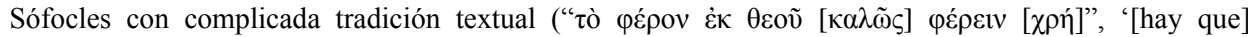
soportar [noblemente] lo que te es asignado por la divinidad', Oed. Col. 1694) o dos momentos de Fenicias de Eurípides: Yocasta recuerda lo cruel que ha sido el destino con la estirpe de Edipo, pero de

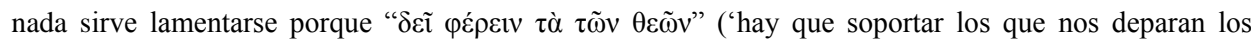

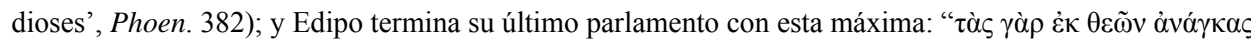

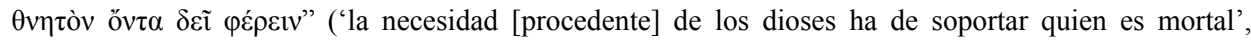

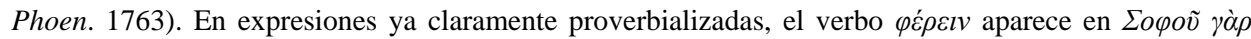

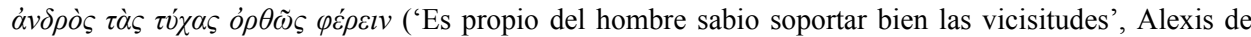

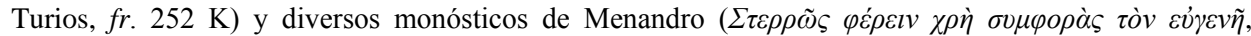
'El noble debe soportar con fortaleza las desgracias', 721; cf. 15, 392, 657).

${ }^{17}$ Algo muy similar leemos en otra de sus obras: "Quod sors feret, feremus aequo animo" ('Lo que nos depare la suerte, lo soportaremos con ánimo sereno', Ter. Phorm. 138).

${ }^{18}$ Hay vacilación en cuanto al infinitivo que contiene esta sentencia, ya que las fuentes primarias presentan vitari (Gell. 17.14.4, Erasm. Adag. 1.3.14), mientras que las ediciones de las sentencias publilianas optan por mutari (Orelli, 1824, p. 16; Zell, 1829, p. 9; Ribbeck, 1855, p. 271; Meyer, 1880, p. 30; $c f$. Sánchez Doncel, 2003, n 3061), quizás por influencia de la siguiente sentencia que citamos en el cuerpo del texto (en la que se usa mutare). Viendo las sucesivas ediciones, parece evidente que la tradición ha preferido claramente el verbo mutari (también en su versión española, como veremos).

${ }^{19} \mathrm{El}$ verbo ferre aparece también en Viriliter feras quae necesse est; dolor enim patientia vincitur, ('Soportarás virilmente lo que es necesario; pues el dolor se vence con paciencia', Ps. Publil. Ap. 138). Aunque aplicable a otras situaciones y con una formulación diferente, otra sentencia de Publilio Siro puede entenderse de modo similar a estas: Nil est miserius, quam ubi pudet quod feceris ('Nada es más miserable que avergonzarse de lo que has hecho', N56). Esta mención de lo que se ha hecho nos trae a la mente las palabras de Aníbal en su parlamento al verse derrotado por Escipión ("Praeterita magis reprehendi possunt quam corrigi", 'Los hechos pasados más se pueden reprender que corregir', Liv. 30.30.7) y, especialmente, refranes españoles del tipo A lo hecho, pecho (47975), que cuenta con múltiples reformulaciones (A lo hecho, ruego y pecho, 54966; A mal fecho, ruego e pecho, 48061; Pues esto es hecho, hay que tener pecho, 55391; Quisiera escarmentar en cabeza ajena; mas al hecho, ruego y pecho, 22066). Asimismo, se registra el refrán Hecho lo que se requiere, suframos lo que viniere 
dievales, se registran variaciones con mantenimiento del verbo ferre (Ferendum est quod mutari non potest, 'Hay que soportar lo que no se puede cambiar', Garate, $1998, \mathrm{n}^{\circ}$ 985) o con cambio de verbo (Quod vitare nequis, audaci suscipe mente, 'Lo que no puedas evitar, afróntalo con espíritu audaz', Walther, 1963-1969,

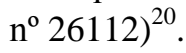

En época argéntea, Séneca nos dejó un pasaje posteriormente proverbializado, por completo equivalente a las unidades anteriores, pero en el que se utiliza el verbo deponente pati $^{21}$ : "Optimum est pati quod emendare non possis" ('Lo mejor es padecer lo que no puedes remediar', Ep. 107.9) y plegarse a la voluntad de la divinidad, que es autora y causa de todo lo que existe. Consecuentemente, en uno de sus tratados morales, considera que "unum est levamentum malorum ingentium: pati et necessitatibus suis obsequi' ('hay un único alivio para los grandes males: padecerlos y prestarse a sus exigencias', Ira, 3.16.1). En este sentido, poco después Epicteto (Ench. 2; 14) argumentó que no tiene sentido rechazar lo que no depende de uno mismo sino de la naturaleza.

En español tenemos equivalentes bastante literales que oscilan entre mudar (como la versión modificada de Publilio: Lo que no se puede mudar, sufrirlo has, 48094) y remediar (según la primera cita de Séneca: Lo que no se puede remediar, se ha de aguantar, 48093). Otros refranes sinónimos apelan a la paciencia que hay que tener (A lo que no puede ser, paciencia, 48081; Donde no hay remedio, haya paciencia, 48095), entroncando con otras muchas paremias que presentan esta actitud como la adecuada ante la adversidad ${ }^{22}$.

(48118), que combina la ya imposible de cambiar realización de algo con la idea de soportar lo que nos depare el futuro. Por otro lado, se recopila como proverbial una oración de Tácito que dice: "Defleri magis quam defendi possunt" ('Más pueden lamentarse que rechazarse', Ann. 1.58.5); en este caso, los paremiógrafos indican que se refiere también al hecho de tener que aceptar lo pasado como irremediable (Herrero Llorente, 1992, n 1874; Sánchez Doncel, 2003, n 1959), pero en realidad se trata de una interpretación un tanto libre de las palabras del noble germano Segestes remedadas por el historiador romano, seguramente fruto de la repetición descontextualizada de este pasaje.

${ }^{20}$ Nótese que en estas dos paremias también se hace patente la vacilación entre vitari y mutari.

${ }^{21}$ Este verbo es frecuentemente usado en unidades referidas a la ataraxia y se relaciona etimológica y semánticamente con el concepto de paciencia, entendido en su sentido original ('resistencia y perseverancia ante el sufrimiento'). No podemos citar todos los testimonios de este verbo, pero basten dos ejemplos: Plauto lo utiliza de forma paronomástica en relación con potiri en un verso proverbializado ("Fortiter malum qui patitur idem post potitur bonum", 'Quien padece con valentía un mal después consigue un bien', Asin. 324; Walther, 1963-1969, nº 9833); y también lo encontramos en una supuesta carta de Dido a Eneas que Ovidio escribió en plena época de Augusto, al servicio de la gloria de Roma y de la identidad romana pregonada por el Emperador ("Vsu fortiter edisco tristia posse pati", 'Con la práctica voy aprendiendo que las desgracias se pueden padecer con valentía', Her. 7.179-180).

${ }^{22}$ Comentamos esta tradición en otra ocasión (Pascual López, 2015, pp. 40-41). 


\section{LA RESIGNACIÓN COMO SOLUCIÓN}

El verbo ferre también aparece -constituyendo una paronomasia con flere- en una nueva sentencia de Publilio, en la que se censura el lamento y la falta de entereza de ánimo: Necessitatem ferre, non flere addecet ('No conviene lamentar la necesidad, sino soportarla', N58) ${ }^{23}$. En español contamos con equivalentes un tanto libres como Mejor es resignarse que lamentarse (48086) o Más vale padecer todo mal que mal tolerar (48083).

Según el corpus publiliano, tampoco tiene sentido temer lo que el destino nos depare, pues su propia fatal inevitabilidad no deja lugar a ningún miedo, que enturbiaría la serenidad con la que debe afrontarse la adversidad; en realidad, la eliminación de todos los temores es una condición sine qua non para la consecución de la tranquilidad de ánimo y de la ataraxia (cf. Epict. Ench. 12). Entre estas sentencias leemos que Stultum est timere quod vitari non potest ('Es necio temer lo que no se puede evitar', Ps. Publil. 353, Ap. 100) ${ }^{24}$. En español, el verbo vitare se adapta como excusar en dos refranes, siendo uno más literal por mencionar explícitamente la falta de cordura y el temor (Gran locura es temer lo que no se puede excusar, 60126), mientras que el otro es una versión más libre (Lo que no se puede excusar, resistirlo sin temblar, 21505). En un tercer refrán español esta tradición se ha fundido con una distinta ${ }^{25}$ : Tan malo es no querer pasar lo que no se puede excusar, como desear lo que no se puede alcanzar (780).

El temor es una aflicción que puede, fácilmente, derivar en ganas de huir, por lo que hay que relacionarlo con Ferme fugiendo in media fata incurritur ('Rehuyéndolos, uno se precipita casi siempre sobre los hados', Ps. Publil. 136). En realidad, se trata de una variación mínima sobre una afirmación que leemos en Livio, cuando explica que Alejandro de Épiro no pudo eludir la muerte que se le había predicho: "Ferme fugiendo in media fata ruitur" ("Rehuyéndolos, uno se abalanza casi siempre sobre los hados', 8.24.3), porque -si se nos permite la fusión de fuentes- siempre "fata viam invenient" ('los hados hallarán el camino', Verg. Aen. $3.395^{26}$ ). En español encontramos también continuación de esta idea de tratar de huir del destino, ya sea presentándolo de forma objetivamente generalizada (Nadie puede huir de lo que le ha de venir, 24382; Nadie puede huir de su ventura, 24383), ya sea

${ }^{23}$ Sin continuidad formal, sino tan solo semántica, los compendios paremiográficos recogen la unidad tardía De re irreparabile ne doleas ('No te aflijas por lo irreparable', Herrero Llorente, 1992, n 1819; Sánchez Doncel, 2003, n 1906).

${ }^{24}$ Como se comprobará, en esta sentencia considerada apócrifa se vuelve a la idea de lo inevitable y reaparece el infinitivo vitari, de cuya alternancia con mutari en otra sentencia publiliana ya hemos hablado.

${ }^{25}$ En concreto, la necesidad de moderar los deseos y adaptarlos a lo posible, de lo cual hemos hablado en otro lugar (Pascual López, 2015, pp. 35-37).

${ }^{26}$ Como indica Tosi (2007 [1991], no 854) esta expresión es registrada por sentencia medieval por Walther (1963-1969, no 8887). 
ridiculizando tal actitud (Gran desatino es querer huir cada cual de su sino, 24385; Gran locura es pretender hurtarse el hombre a su ventura, 24384), enlazando así con las paremias relacionadas con Stultum est timere... que acabamos de aducir.

Si no hay que temer la necesidad ni puede rehuirse, la única opción que nos queda es conformarnos, sufrir y aceptar lo que nos sucede. Por tanto, rendirse y resignarse a la propia suerte se concibe como la única manera de vencer la adversidad. A partir de esta aparente paradoja entre vencer y ser vencido se ha construido un tópico que encontramos en diferentes pasajes de la literatura latina y que llega hasta nuestro refranero.

Entre los monósticos atribuidos a Catón el Censor, leemos: Qui vinci sese patitur pro tempore, vincit ('Quien en el momento oportuno soporta ser vencido, vence', 42). Por tanto, dentro de ese imperativo a sufrir y padecer que hemos estado viendo a lo largo de este artículo, se incluye el aceptar la propia e inapelable derrota. Ovidio, a su vez, traslada el lugar común al terreno amoroso, indicando que conviene ser condescendiente y servicial: "Cede repugnanti; cedendo victor abibis" ('Cede a quien te lleva la contraria; cediendo saldrás vencedor', Ars am. 2.197). Por su parte, Petronio recurre al tópico para advertir que en las disputas siempre sale ganador quien se retira a tiempo: "Semper in hac re qui vincitur, vincit" ('En este asunto siempre vence quien es vencido', Satyr. 59). Por último, Quintiliano lleva el topos al ámbito de la oratoria, señalando que en un juicio hay que evitar la violencia y saber contenerse, puesto que "ubi vinci necesse, expedit cedere" ('donde necesariamente hay que ser vencido, conviene ceder', Inst. 6.4.16).

En consecuencia, vemos que la aplicación del tópico en la literatura latina más bien no está vinculada con la necesidad y la actitud ante el destino. En cambio, en algún momento este lugar común mudó de ámbito de aplicación, ya que en español es el contexto predominante. Este viraje se ve en el hecho de que, frente a las equivalencias más literales que conservan los verbos ceder y vencer (Quien cede, vence, 12193; Cediendo se vence, 19475; Quien sabe ceder, sabe vencer, 12194), la mayoría de nuestros refranes que siguen esta línea ha sustituido el verbo ceder por sufrir (Quien sufrió, venció, 22511; Quien supiere sufrir, sabrá vencer, 48163; Para conquistar alturas, sufrir amarguras, 22518; El hombre sufrido, libre está de verse perdido, 48158) o su sinónimo padecer (Si quieres vencer, aprende a padecer, 48147; Quien quisiere vencer, aprenda a padecer, 1522; Para vencer es preciso padecer, 22519), al tiempo que también existen versiones más libres en las que se recurre a la paciencia como talante que conduce al éxito (Al fin vence quien paciencia tiene, 48160; Con la paciencia todo se logra, 48165; La paciencia, las más veces acierta, 48159; La paciencia ha vencido más batallas que el Cid, 48161).

La clave de este triunfo radica en el hecho de que la paciencia y el habituarse al sufrimiento tienen un efecto lenificador. Así, Horacio considera que "levius fit patientia / quidquid corrigere est nefas" ("la paciencia hace más llevadero lo que no se 
puede enmendar', Carm. 1.24.19-20) ${ }^{27}$. Por su parte, Ovidio echa mano jocosamente de este tópico aplicándolo a los defectos de la amada, a los cuales debe acostumbrarse el amante para que dejen de molestarle: "Quod male fers, assuesce; feres bene" ('Acostúmbrate a lo que soportas mal: lo soportarás bien', Ars am. 2.647). Mayor carácter moral y seriedad le confiere Séneca a esta idea, que se convierte en un modo de vida: "Necessitas fortiter ferre docet, consuetudo facile" ('La necesidad enseña a soportarla con fortaleza; la costumbre [enseña a soportarla] fácilmente', Tranq. 10.1$)^{28}$. En las derivaciones de esta idea, nuestro refranero suele recurrir al sustantivo paciencia (Con paciencia, el mayor mal se sobrelleva, 48172; A la mayor dolencia vence la paciencia, 48170; A cualquier dolencia, es remedio la paciencia, 48168), aunque un antiguo refrán prefiere costumbre (La costumbre luenga amansa los dolores, 19539), como en la cita senequiana.

\section{EL SUFRIMIENTO Y LA FELICIDAD}

Hay dos sentencias de Publilio equivalentes que se fundan en sendas antítesis: entre los adjetivos difícil/fácil (Feras difficilia ut facilia perferas, 'Soporta lo difícil para poder resistir lo fácil', F23) y los verbos herir/beneficiar (Feras quod laedit ut quod prodest perferas, 'Soporta lo que te hiere, para que puedas resistir lo que te beneficie', F25). En ambos casos, se insta a sufrir la adversidad como manera de entrenar el ánimo y, después, ser capaz de no ensoberbecerse en la prosperidad. Se trata de un tópico de largo recorrido ${ }^{29}$ y de raigambre estoica, que no solo considera que el infortunio permite ejercitar la virtud, sino que la serenidad en la dicha no permite que nuestro ánimo se debilite (Sellars, 2006, p. 102; Sen. Prov. 4.6; 4.9-10), de ahí la necesidad de abstinencia y autocontrol. Estas sentencias publilianas hallan su eco en especial en el refrán Comporta lo pesado y llevarás bien lo ligero (48100), aunque también en otros del tipo Traga lo peor para que la alegría sea mayor (Sbarbi, 1943, p. 54) o Menester es padecella por vivir después sin ella (1516).

Esta relación entre el dolor y la felicidad deriva de una suposición lógica que impera en el estoicismo y que Long (2004 [1975]) resume como sigue:

Si la providencia de la Naturaleza lo abarca todo, entonces cualquier suceso que cause injuria o sufrimiento ha de ser interpretado como algo que, si todos los hechos fueran conocidos, lo reconocerían los hombres racionales como beneficioso. (p. 168)

${ }^{27}$ Véanse otras citas similares de Horacio en Pascual López (2015, pp. 39-40) y en Jiménez Gazapo, Morillas Gómez \& Morillo Ruiz (2012, p. 222), donde se cita también un pasaje de Arquíloco (fr. 7.5-6

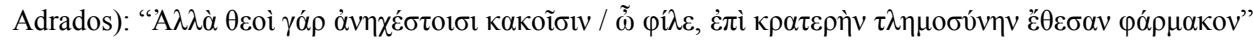
('Pero los dioses, querido amigo, han puesto como medicina para los males incurables el coraje')

${ }^{28}$ Sobre el tema del poder de la necessitas, véase Tosi (2007 [1991], $\mathrm{n}^{\circ}$ 501-502).

${ }^{29}$ No vamos a tratarlo aquí de forma exhaustiva, pues de él nos hemos ocupado anteriormente (Pascual López, 2015, p. 38). 
A tenor de esto, dice Epicteto (Ench. 49) que el sabio estoico quiere comprender la naturaleza y seguirla; con todo, la visión humana está sujeta a unos límites que no le permiten ver este orden natural que, en el fondo, es el mejor posible. De este optimismo nace la creencia de que No hay mal que por bien no venga (13204), de lo que ya nos ocupamos (Pascual López, 2015, p. 35) y que se encuentra ya en Homero

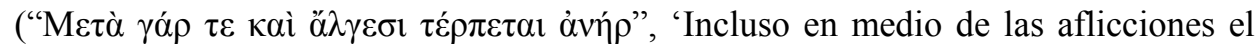
hombre se alegra', $O d$. 15.400), pero también la creencia de que puede obtenerse placer del recuerdo de las penalidades pasadas, como si con el tiempo se ampliara la perspectiva y se vislumbrara ese orden cósmico perfecto.

En la literatura latina son numerosos los pasajes en que aparece esta idea, pero con toda seguridad se trata de un tópico preexistente, ya formulado paremiológica-

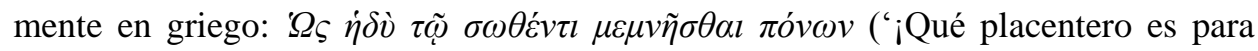
quien se ha salvado recordar sus fatigas!', Men. Monost. 859). Una variante casi idéntica se incluye entre los fragmentos de Eurípides $\left(f r .133 \mathrm{~N}^{2}\right)^{30}$, autor al que Cicerón también hace remontar el tópico a través de su propia adaptación al latín: "Suavis laborum est praeteritorum memoria" ('Es dulce el recuerdo de las fatigas pasadas', Fin. 2.32.105). En el mismo pasaje, Cicerón ofrece una reformulación del tópico de su propia cosecha ("Iucunda memoria est praeteritorum malorum", 'Es grato el recuerdo de los males pasados'), así como una paremia latina (Iucundi acti labores, 'Son agradables las fatigas ya realizadas', Erasm. Adag. 2.3.43; Tosi, 2007 [1991], $\mathrm{n}^{\mathrm{o}}$ 1620). E incluso el orador vuelve a hacer alusión a la idea en una de sus cartas: "Habet praeteriti doloris secura recordatio delectationem" ('Tiene placer el recuerdo seguro de los dolores pasados', Fam. 5.12.4).

Por otro lado, la arenga de Eneas a sus hombres a la que hemos aludido al inicio incluye también este tópico: "Forsan et haec olim meminisse iuvabit" ('Quizás algún día os será grato recordar esto', Verg. Aen. 1.203) ${ }^{31}$. Y unas palabras más explícitas aparecen categóricamente en boca de Anfitrión: "Quae fuit durum pati / meminisse dulce est" ('Lo que fue duro de padecer es dulce de recordar', Sen. Herc. fur. 656-657) ${ }^{32}$.

En español se indica que el mal pasado es menos doloroso que el futuro ( $\mathrm{El} \mathrm{mal}$ que se recuerda duele menos que el que se espera, 38170; El mal ya sufrido duele menos que el temido, 21046), porque Cuando ya es pasado, es el bien apreciado (48934). Como hizo Cicerón al adaptar a Eurípides, se califica este mal recordado como dulce (El mal ya pasado, dulce es contado, 48935), a veces estableciendo una antítesis (Lo que fue amargo pasado, es dulce recordado, 48936; Lo que fue amargo

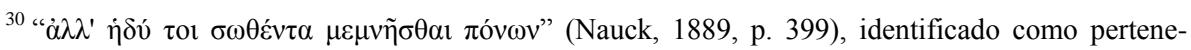
ciente a Andrómeda según Estobeo (Flor. 29.57).

${ }^{31}$ Cabe también recordar un pasaje ya citado de Ovidio (Am. 3.11a.7).

${ }^{32}$ En el corpus publiliano se incluyen dos sentencias antónimas: la apócrifa está en sintonía con esta tradición (Dulcis malorum praeteritorum memoria, 'El recuerdo de los males pasados es dulce', Ps. Publil. 104) y la legitimada defiende claramente la idea opuesta (Post calamitatem, memoria alia est calamitas, 'Después de una desgracia, su recuerdo es otra desgracia', P48).
} 
de pasar, es dulce de recordar, 19546). A todos estos refranes podemos añadir otro (Grato es recordar lo pasado, si se está contento y fue malo; pero si fue dichoso y se está en pobreza, es doloroso, 40544) que, de modo un tanto escéptico, subvierte la tradición al indicar que la sensación del recuerdo depende de la situación.

\section{CONCLUSIONES}

El conjunto de paremias comentadas en estas páginas viene a concluir que hay trances inevitables por los que los seres humanos tienen que pasar, no solo porque no pueden evitarlos, sino porque incluso gracias a ellos acabarán obteniendo algún beneficio. El sesgo de esta cosmovisión se funda en la formulación de leyes universales, como si las paremias solo estuvieran reflejando lo que es objetivamente cierto y constituyeran un acto de habla meramente representativo; en consecuencia, sobre esta base es fácil acuñar paremias que claramente sean directivas, prescribiendo la conducta adecuada en función de esa supuesta ley natural.

El orden cósmico que gobierna la naturaleza según el estoicismo se contagia a la percepción de la realidad que transmiten las paremias representativas, en las cuales reina un sentimiento de fatalidad que priva de sentido a cualquier enfrentamiento con el destino. Con este campo abonado, las paremias prescriptivas promueven abiertamente una conducta conformista que, a fin de cuentas, refrena los deseos humanos y frustra cualquier aspiración a unas mejores condiciones de vida: la fatalidad externa se convierte en un fatalismo y un derrotismo internos.

Esta fatalidad pagana no habría tenido el empuje que tiene en nuestro refranero si no hubiera unido fuerzas con el providencialismo cristiano. Aunque en el estoicismo la fatalidad no era arbitraria (sino que obedecía a un orden perfecto de cosas), las limitaciones de la perspectiva humana para captar la razón de ese orden -que los propios estoicos señalaban- quedan contrarrestadas por la imagen de un dios providente y benevolente, que ayuda a aceptar la realidad por muy adversa que sea. Consideramos que ahí está la clave del triunfo de esos preceptos estoicos en nuestro refranero y, por tanto, de la pervivencia en él de numerosas paremias o formulaciones sentenciosas del mundo antiguo, que a menudo se revisten de un mayor optimismo que las fuentes clásicas, gracias a la esperanza en una vida en el más allá.

Si revisamos las paremias que hemos visto en estas páginas, veremos que muchas de ellas se fundan en figuras como la paradoja, la antítesis y la paronomasia. Esto es significativo en tanto que estas unidades tienen que invertir la percepción humana: deben hacer ver que lo aparentemente adverso contiene, en el fondo, la semilla de la felicidad. Epicteto (Ench. 5, 16, 20, passim) insiste en que las cosas no son malas, sino solo las opiniones, las representaciones mentales que sobre ellas nos hacemos, porque son estas lo que en realidad nos perturba. Recurrir a figuras retóri- 
cas de oposición hace percibir como cercanas o complementarias realidades que, en un primer momento, se perciben como incompatibles.

En el fondo, "la creencia fatalista es sumamente conservadora" (Miguel, 2000, p. 79). Por ello, las paremias subversivas que hemos localizado son claramente minoritarias. Nuestro acervo paremiológico nos conmina a aceptar con resignación lo inevitable y, de este modo, el refranero se erige en un mecanismo de control que amilana todo intento de ruptura con el orden establecido de acuerdo con unas estructuras de poder claramente manifiestas. 


\section{BIBLIOGRAFÍA}

Alciato, A. (1549). Los emblemas de Alciato traducidos en rhimas españolas. Lyon: Macé Bonhomme \& Guillaume Rouille. Edición facsímil disponible en http://www.emblems.arts.gla. ac.uk/alciato/books.php?id=A49a

- (1550). Emblemata. Lyon: Macé Bonhomme \& Guillaume Rouille. Edición facsímil disponible en http://www.emblems.arts.gla.ac.uk/alciato/books.php?id=A50a

Anscombre, J.-C. (2010). Las formas sentenciosas: un fenómeno lingüístico. Revista de Investigación Lingüistica, 13, 17-43.

Arewa, E. O. \& Dundes, A. (1964). Proverbs and the Ethnography of Speaking Folklore, American Anthropologist, 66 (6), 70-85. DOI: 10.1525/aa.1964.66.suppl_3.02a00040.

Briggs, C. L. (1985). The Pragmatics of Proverb Performances in New Mexican Spanish. American Anthropologist, 87 (4), 793-810. DOI: 10.1525/aa.1985.87.4.02a00030.

Calero Fernández, M. Á. (1991). La imagen de la mujer a través de la tradición paremiológica española (Lengua y cultura) (Tesis doctoral). Lleida: Universitat de Barcelona.

Corpas Pastor, G. (1996). Manual de fraseología española. Madrid: Gredos.

Dobrovol'skij, D. \& Piirainen, E. (2005). Figurative Language. Cross-Cultural and CrossLinguistic Perspectives. Amsterdam \& Boston: Elsevier.

Domínguez Barajas, E. (2010). The Function of Proverbs in Discourse: The Case of a Mexican Transnational Social Network. Berlin \& New York: Walter de Gruyter Mouton.

Doval, G. (1996). Diccionario de expresiones extranjeras. Madrid: Ediciones del Prado.

- (1997). Refranero temático español. Madrid: Ediciones del Prado.

Forgas Berdet, E. (1982). Ensayo de reconstrucción paremiológica de cultura material: los ciclos del pan y del vino en las paremias hispanas. Barcelona: Universitat de Barcelona.

- (1992). Lingüística, etnolingüística y paremiología. En: J. A. Bartol Hernández, J. de Santiago Guervós \& J. F. García Santos (Coords.), Estudios filológicos en homenaje a Eugenio de Bustos Tovar (vol. 1, pp. 293-302). Salamanca: Universidad de Salamanca.

Garate, G. (1998). 27.173 Atsotitzak. Refranes. Proverbes. Proverbia. Bilbao: Fundación Bilbao Bizkaia Kutxa Fundazioa.

Herrero Llorente, V.-J. (1992). Diccionario de expresiones y frases latinas. Madrid: Gredos.

Jiménez Gazapo, P., Morillas Gómez, M. \& Morillo Ruiz, R. (2012). La Musa sensata. Aforismos y proverbios en la sátira latina. Madrid: Cátedra.

Kirshenblatt-Gimblett, B. (1973). Toward a Theory of Proverb Meaning. Proverbium, 22, 821-827.

Langlotz, A. (2006). Idiomatic Creativity. A Cognitive-Linguistic Model of Idiom-Representation and Idiom-Variation in English. Amsterdam \& Philadelphia: John Benjamins.

Long, A. A. (2004 [1975]). La filosofia helenística. Estoicos, epicúreos, escépticos (trad. de P. Jordán de Urríes). Madrid: Alianza.

Martínez Kleiser, L. (1953). Refranero general ideológico español. Madrid: Hernando.

Meyer, W. (Ed.) (1880). Publilii Syri Mimi Sententiae. Leipzig: Teubner.

Miguel, A. de (2000). El espíritu de Sancho Panza. El carácter español a través de los refranes. Madrid: Espasa.

Nauck, A. (1889). Tragicorum Graecorum fragmenta. Leipzig: Teubner.

Norrick, N. R. (2007). Proverbs As Set Phrases. En: H. Burger, D. Dobrovol'skij, P. Kühn \& N. R. Norrick (Eds.), Phraseology. An International Handbook of Contemporary Research (vol. 1, pp. 381-393). Berlin \& New York: Walter de Gruyter.

Orelli, J. K. (Ed.) (1824). Carmina sententiosa poetarum veterum latinorum et recentiorum quorundam. Tomus Prior. Publii Syri Mimi et aliorum Sententaie cum Laberii prologo et fragmentis moralibus. Leipzig: Friedrich Fleischer. 
Ortiz García, P. (Ed.) (1995). Tabla de Cebes. Musonio Rufo: Disertaciones. Fragmentos menores. Epicteto: Manual. Fragmentos. Madrid: Gredos.

Pascual López, X. (2012). Fraseología española de origen latino y motivo grecorromano (Tesis doctoral). Lleida: Universitat de Lleida. Disponible en http://www.tdx.cat/handle/10803/ 84020

- (2015). El conformismo como motivo grecorromano en las paremias españolas. Paremia, 24, 31-42. Disponible en http://cvc.cervantes.es/lengua/paremia/pdf/024/003_pascual.pdf

Pawley, A. \& Syder, F. H. (2000). The One Clause at a Time Hypothesis. En: H. Riggenbach (Ed.), Perspectives on Fluency (pp. 167-191). Ann Arbor, MI: University of Michigan Press.

Penadés Martínez, I. (2006). El valor discursivo de los refranes. ELUA. Estudios de Lingüística, 20, 287-304.

Piirainen, E. (2008). Figurative Phraseology and Culture. En: S. Granger \& F. Meunier (Eds.), Phraseology. An Interdisciplinary Perspective (pp. 207-228). Amsterdam \& Philadelphia: John Benjamins.

Pruss, A. R. \& Gale, R. M. (2005): Cosmological and Design Arguments. En: W. J. Wainright (Ed.), The Oxford Handbook of Philosophy of Religion (pp. 116-137). New York: Oxford University Press.

Ribbeck, O. (Ed.) (1855). Scenicae Romanorum poesis fragmenta. Vol. II. Comicorum Latinorum praeter Plautum et Terentium reliquiae. Leipzig: Teubner.

Sánchez Doncel, G. (2003). Diccionario de latinismos y frases latinas. Madrid: Noesis.

Sbarbi, J. M. (1943). Gran diccionario de refranes de la lengua española. Buenos Aires: Joaquín Gil.

Sellars, J. (2006). Stoicism (Ancient Philosophies). Durham: Acumen.

Sevilla Muñoz, J. (1988). Hacia una aproximación conceptual de las paremias francesas y españolas. Madrid: Complutense.

Sevilla Muñoz, J. \& Crida Álvarez, C. A. (2013). Las paremias y su clasificación. Paremia, 22, 105-114.

Telija, V. N., Bragina, N., Oparina, E. \& Sandomirskaja, I. (1998). Phraseology as a Language of Culture: Its Role in the Representation of a Collective Mentality. En: A. P. Cowie (Ed.), Phraseology. Theory, Analysis, and Applications (pp. 55-75). Oxford \& New York: Oxford University Press.

Tosi, R. (2007 [1991]). Dizionario delle sentenze latine e greche. Milano: Bur.

Veyrat Rigat, M. (2008). Aproximación lingüística al estudio del refrán como unidad comunicativa. Dialogía. Revista de lingüística, literatura y cultura, 3, 5-31.

Walther, H. (1963-1969). Proverbia sententiaeque latinatis medii ac recentionis aevi. Göttingen: Vandenhoeck \& Ruprecht.

White, G. M. (1987). Proverbs and Cultural Models. An American Psychology of Problem Solving. En: D. Holland \& N. Quinn (Eds.), Cultural Models in Language and Thought (pp. 151-172). Cambridge: Cambridge University Press.

Wray, A. \& Perkins, M. (2000). The Functions of Formulaic Language: An Integrated Model. Language and Communication, 20 (1), 1-28. DOI: 10.1016/S0271-5309(99)00015-4.

Zell, K. (Ed.) (1829). Publii Syri Sententiae cum F. I. Desbillontii emendationibus nunc primum editis Dionysii Catonis Disticha de moribus ad filium, Caelii Symposii Aenigmata. Stuttgart: Karl Hoffmann. 
